\title{
Poliomielite, filantropia e fisioterapia: o nascimento da profissão de fisioterapeuta no Rio de J aneiro dos anos 1950
}

\author{
Poliomyelitis, philanthropy and physiotherapy: the birth \\ of the career of physiotherapist in Rio de Janeiro in the 1950s
}

Fabio Batalha M onteiro de Barros ${ }^{1}$

Abstract The polio epidemics in the country and especially in Rio de Janeiro left hundreds of children with sequels in the 1950s. The public outcry over the polio epidemic, the reports in the press and the association of experienced physicians with businessmen, bankers and relatives of victims created the conditions for the emergence of a philanthropic entity to combat infantile paralysis. The Brazilian Beneficent Association of Rehabilitation (BBAR) was founded in 1954, and two years later the association created the School of Rehabilitation of Rio de Janeiro (SRRJ), the first institution to graduate physiotherapists in the country. This article presents a socio-historical analysis of the establishment of physiotherapy as a profession in Rio de Janeiro in the course of the creation and accreditation of the School of Rehabilitation. It is concluded that the polio epidemics played a central role in the creation of the School of Rehabilitation and that conversely this institution had a strong influence in the recognition of physiotherapy as a health profession in the country. Key words Physiotherapist, Physiotherapy, Polio, BBAR, SRRJ, Rehabilitation
Resumo As epidemias de poliomielite no país e especialmente no Rio de Janeiro deixaram centenas de crianças com seqüelas durante os anos 1950. 0 clamor social diante da epidemia de poliomielite, as matérias na imprensa e a associação demédicos experientes a empresários, industriais, banqueiros e familiares das vítimas de poliomielite criaram as condições para o surgimento de uma entidade filantrópica deluta contra a paralisia infantil. A Associação Brasileira Beneficente de Reabilitação ( $A B B R$ ) foi fundada em 1954 e, dois anos depois, criou a Escola de Reabilitação do Rio de Janeiro (ERRJ), a primeira instituição a formar fisioterapeutas em nível superior no país. Este artigo realiza uma análise sociohistórica da profissionalização da fisioterapia no Rio de Janeiro, ao longo do processo de criação e reconhecimento da ERRJ. Ao final, conclui-se que a epidemia de poliomielite teve papel central na criação da Escola de Reabilitação eque esta instituição, por sua vez, influenciou fortemente no reconhecimento e na profissionalização da fisioterapia no país.

Palavras-chave Fisioterapeuta, Fisioterapia, Poliomielite, ABBR, ERRJ, Reabilitação 


\section{Introdução}

A profissão de fisioterapeuta foi regulamentada no Brasil no dia 13 de outubro de 1969. O Decreto-lei no 938 a definiu como profissão de nível superior, cabendo ao fisioterapeuta, de forma privativa, a real ização de "métodos e técnicas fisioterápicos com a finalidade de restaurar, desenvolver e conservar a capacidadefísica do cliente" ${ }^{\prime 1}$.

A Junta M ilitar que governava o país em 1969, ao assinar o Decreto-lei no 938 , regulamentou 0 exercício das profissões defisioterapeuta edeterapeuta ocu pacional, definindo suasáreas de atuação e formação. 0 exercício profissional na área da fisioterapiatornou-sedesdeentão exclusividade de fisioterapeutas formados em cursos de nível superior. Antes do Decreto-lei no 938, quatro projetos delei tramitaram pelo Congresso $\mathrm{N}$ acional, desde 1958, na tentativa de regulamentar a profissão e formação dos fisioterapeutas no país ${ }^{2-5}$.

A história da profissão de fisioterapeuta no país tem sido objeto de estudo de professores e pesquisadores, principalmente fisioterapeutas vinculados a programas de pós-graduação em áreas como saúde coletiva, educação e na própria fisioterapia. Diversos trabalhos têm abordado períodos recentes da profissionalização da fisioterapia, tendo o Decreto-lei no 938 como ponto de partida de suas análises, passando pela criação dos Consel hos de Fisioterapia e de Terapia Ocupacional nos anos 1970 e utilizando, por vezes, a história como pano de fundo para suas produções acadêmicas ${ }^{6-10}$. Dentre os trabalhos cujo objeto deestudo está mais diretamenterelacionado com a história da fisioterapia merecem destaque a monografia de Figueirôa ${ }^{11}$, os artigos de Define ${ }^{12}$, Oliveira ${ }^{13}, \mathrm{M}^{2}$ arques $^{14}, \mathrm{~N}$ ascimento ${ }^{15}$, Barros $^{16}$ e Sanchez ${ }^{17,18}$, e as dissertações de Oliveira ${ }^{19}$, N ascimento ${ }^{20}$, Reis ${ }^{21}$ e Soares $^{22}$.

Embora seja consenso entre todos os autores queo Decreto-lei no 938 seja um marco institucional importante para o estabelecimento da profissão de fisioterapeuta no país, pouco se produziu sobre as décadas que 0 antecederam e processos que 0 viabilizaram. 0 presente artigo pretende justamente discutir o início da profissionalização da fisioterapia nos anos 1950, a partir da análise histórica da criação e reconhecimento da Escola de Reabilitação do Rio de Janeiro (ERRJ).

A ERRJ foi criada pela Associação Brasileira Beneficente de Reabilitação (ABBR) em 1956 e foi a primeira instituição no país a oferecer em caráter regular um curso de graduação em fisioterapia ${ }^{23}$. Ao longo deste artigo, serão analisadas as influências de diferentes acontecimentos do cenário regional, nacional einternacional relacionados direta ou indiretamente com a criação e reconhecimento daERRJ. As principaisfontes utilizadas neste artigo são documentos pesquisados em acervos pessoais e alguns da própria $A B B R$, além de periódicos de grande circulação no Rio de Janeiro (à época Capital Federal) que oferecem informações sobre as epidemias de poliomielite, a mobilização da sociedade carioca em ações de filantropia, a influência de organismos internacionais na criação de centros de reabilitação e o funcionamento da Escola de Reabilitação do Rio de Janeiro. Serão analisados também documentos oficiais do Conselho Federal de Educação e Projetos de Lei relacionados ao período dereconhecimento daERRJ.

\section{Poliomielite, reabilitação eagênciasinternacionais}

As epidemias de poliomielite influenciaram fortemente 0 desenvolvimento da fisioterapia em grande parte do mundo. A primeira grande epidemia de pólio nos Estados Unidos, em 1916, infectou mais de 27.000 pessoas em 26 estados, resultando em aproximadamente 6.000 mortese milhares de casos de paralisia ${ }^{24}$. Ao longo da epidemia norte-americana (1916 a 1955), foram infectadas em média 38.000 pessoas por ano, sendo que em 1952 chegou-se a alarmante taxa de infecção de 35 em cada 100.000 habitantes $^{25}$.

A poliomielite é uma doença viral, que atingiu principalmente crianças dezero a quatro anos (não vacinadas), causando a morte por comprometimento dos músculos respiratórios ou deixando seqüelas com a perda parcial ou total da capacidade de contração dos músculos, quadro conhecido como paralisia flácida aguda ${ }^{26}$.

0 presidente norte-americano Franklin Delano Roosevelt havia contraído pólio em 1921, aos 39 anos de idade. Em 1937, Roosevelt criou a Fundação Nacional para Paralisia Infantil, talvez uma das maiores responsáveis pelos investimentos maciços na pesquisa da vacina contra a pólio. Em 1945, a Fundação Nacional para Paralisia I nfantil, colaborando com a Associação Americana de Fisioterapia, investiu mais de um miIhão de dólares para o avanço da fisioterapia no tratamento da poliomielite paralítica ${ }^{27}$.

Diversos artigos internacionais comparam a importância da pólio como equival enteou superior a das duas grandes guerras mundiais, no que se refere a sua contribuição para o desenvol- 
vimento das técnicas de fisioterapia e da profissão de fisioterapeuta no mundo ${ }^{28-31}$.

Como parte do processo de desenvolvimento da profissão de fisioterapeuta, foi criada a Confederação M undial de Fisioterapia (WCPT) em 1951, na Dinamarca, que em seu primeiro congresso internacional, realizado em Londres no ano de 1953, reuniu cerca de 1.500 participantes de 25 países $^{19}$. Em 1954, aWCPT estava representada no III Congresso M undial dePoliomielite, realizado na cidade de Roma, no qual Albert Sabin e Jonas Salk apresentavam suas experiências com as vacinas contra a poliomielite ${ }^{32}$. Nos anos 1950, a WCPT já mantinha relações formais de colaboração com a Organização Mundial da Saúde (OMS) e o Fundo das N ações Unidas para a I nfância (UNICEF). D entre os objetivos definidos na fundação da WCPT constam a cooperação com agências do sistema das $\mathrm{N}$ ações Unidas eoutras agências internacionais "nos seus esforços para iniciar, desenvolver ou ampliar serviços dereabilitação através do mundo" 33 e 0 oferecimento de consultoria, informação eassistência a agências internacionais, governos e indivíduos para o desenvolvimento de escolas de fisioterapia, oferecendo "pessoal eequipamentos para departamentos de fisioterapia"33.

Durante os anos 1950, diferentes organismos internacionais atuaram na área de reabilitação, dentre eles: Fundo Mundial de Reabilitação, Organização Mundial da Saúde, Organização Internacional do Trabalho, Reabilitação I nternacional, UNICEF, 'Colombo Plan', Federação Mundial deVeteranos e a Administração de Assistência e Reabilitação das Nações Unidas ${ }^{34-36}$. Deacordo com o Departamento de Assuntos Econômicose Sociais das $\mathrm{N}$ ações U nidas, o interesse mundial pela reabilitação ocorreu principalmentepor quatro acontecimentos históricos: as duas grandes guerras mundiais, processo acelerado de urbanização e industrialização (favorecendo a propagação de epidemias e aumento dos acidentes de trabalho), progressos tecnológicos, médicos e das ciências sociais que permitiram a organização dos centros de reabilitação e uma consciência social mais sensível à causa das pessoas portadoras de deficiência ${ }^{37}$.

Segundo especialistas do Comitê de Reabilitação M édica da Organização M undial da Saúde (OMS) , a reabilitação teria como finalidade principal não apenas restabelecer a pessoa afetada à sua condição anterior, mas também desenvolver ao máximo suas funções físicas e mentais. Literalmente, como consta no informe do Comitê, reabilitação não seria apenas a cura física, mas também a cura social e, ao referir-se às vantagens da reabilitação nos países subdesenvolvidos, o texto ressalta que "uma reabilitação, que transforma em produtor útil a um consumidor inútil, representa uma contribuição valiosa ao bem-estar geral" 38 .

0 primeiro informe de reabilitação médica da OM S, datado de 1958, destacava a dificuldade de formação de uma equipe com fisioterapeutas e terapeutas ocupacionais (chamados de ergoterapeutas) , ressaltando que "a formação de uma equipe de fisioterapeutas e ergoterapeutas é uma tarefa tão ou mais difícil quanto a formação de pessoal de cirurgia e de enfermaria" ${ }^{38}$.

Poliomielite no Rio de Janeiro na década de 1950

Existem relatos de casos de poliomieliteno Brasil desde o século XIX. A partir de 1930, diversas capitais brasileirasforam fortemente afetadas pela paralisia infantil: Porto Alegre (1935), Santos (1937), São Paulo e Rio de Janeiro (1939). Nos anos 40, Belém (1943), Florianópolis (1943 e 1947), Recife (1946) e Porto Alegre (1945) ${ }^{39}$.

Nos anos 1950, a epidemia de poliomielite atingia principalmente cidades do interior esurtos importantes ocorreram em algumas capitais como São Paulo e Rio de Janeiro. Em 1953, o Rio de Janeiro registrou sua maior epidemia, atingindo a taxa de 21,5 pessoas infectadas por 100 mil habitantes ${ }^{39}$.

De acordo com N ogueira e Risij ${ }^{39}$, os maiores afetados pela pólio eram crianças e, segundo inquérito sorológico realizado em 1956 no Rio de Janeiro, os grupos de condição socioeconômica mais el evada correspondiam 60 a $70 \%$ dos casos paralíticos conhecidos, demonstrando menor imunidade natural à poliomielite. Tal perfil só viria a ser modificado, segundo os autores, na década de 1960, em que a cobertura vacinal dos mais pobres era mais difícil, aumentando o contágio nas camadas populares.

"A sombra da invalidez sobre uma coletividade" 40 era o título de matéria publicada pelo jornal Correio da M anhã em 1953, ressaltando "a importância médico-social da paralisia infantil, que como se sabe não respeita nem raça, nem idade, nem país e nem clima, causando vítimas no mundo inteiro elevando uma grandepercentagem destas à invalidez temporária ou mesmo definitiva". Em outra página do mesmo jornal, 0 Dr. Oswaldo Pinheiro Campos, médico do Hospital Jesus que atendia a crianças vítimas de poli- 
omielite, declarava o caráter epidêmico da doença no Rio de Janeiro, aparentemente contrariando as autoridades municipais $s^{41}$. Segundo ele, nos três primeiros meses de 1953, "houve doze óbitos de paralisia infantil e 130 casos" $^{42}$ e, referindo-seà ten dência das autoridades municipais em negar a existência de epidemia, ressalta que "é muito mais útil reconhecer e contar uma verdade, embora desagradável, do que encobrir com artifícios de lógica".

As primeiras vacinas (Salk) contra a poliomielite começaram a ser utilizadas no Brasil a partir de 1955 em alguns consultórios e clínicas pediátricas no Rio de Janeiro e São Paulo. Em 1960, foi realizada a primei ra vacinação em massa com a vacina Salk e, em 1961, iniciaram-se grandes campanhas de vacinação em diferentes cidades brasileiras, já com a utilização da vacina Sabin distribuída pelo M inistério da Saúde ${ }^{41}$.

A poliomielite, ou paralisia infantil como era também chamada, não era mais uma das doenças normalmente associadas à pobreza, falta de instrução ou higiene, mas afetava indiscriminadamente a população. Grande parte das crianças atingidas pela poliomielite pertencia às famílias das classes sociais com maior capacidade de articulação social e poder aquisitivo, recursos que foram importantes para a mobilização das elites cariocas em meados dos anos 1950.

\section{Filantropia, política e a fundação da ABBR}

U m grupo de médicos, industriais, banqueiros, comerciantes, militares e senhoras da sociedade está empenhado em promover a recuperação das vítimas da paralisia infantil ou de acidentes que, por falta de um centro especializado, estão condenados a esforços puramenteindividuais eisolados quenem sempre conduz a bom resultado ${ }^{43}$. Assim 0 Globo descreveu em abril de 1956 a criação da ABBR. A matéria intitulada "O Primeiro Centro de Reabilitação das Vítimas de Paralisia Infantil" descrevia as instalações provisórias do centro de reabilitação da ABBR em uma casa no bairro da Tijuca, no Rio de Janeiro, edivulgava os nomes dos integrantes da primeira diretoria da entidade: 0 Presidente éo senhor Percy Charles M urray, diretor presidente do "The National Citibank" e o consel ho deliberativo ficou constituído dos senhores Nilo Colonna dos Santos, Sidney Robert M urray, M ario $M$ archese e M ajor Antonio João Dutra. São vice presidentes os senhores Fernando Iehly de Lemos, O swaldo Benjamin de Azevedo, Ângelo de M oraes Cerne, Jorge Faria, Jose Gonçalvez Portella, Candi- do GuinledeP. M achado, Bert Grand M asson Salgado e H erbert M oses. $O$ Conselho Técnico é presidido pelo Dr. Oswaldo Pinheiro Campos, o Conselho Fiscal pelo M arechal Eurico Gaspar Dutra eo conse Iho consultivo pelo sr. Ormeu Junqueira Botelho ${ }^{43}$.

0 Globo, em agosto de 1956, referia-se àfundação da ABBR como um "humanitário movimento de assistência às vítimas de paralisia infantil" que fazia parte da "campanha de socorro às vítimas de poliomielite" 45 . Segundo o jornal, a ABBR foi idealizada "pelos vários setores da sociedade carioca", dela fazendo parte, inclusive, "vítimas da poliomielite ou parentes destas". A matéria ressal ta ainda a dificuldade do tratamento e seu elevado custo como fatores determinantes para a criação da $\mathrm{ABBR}^{44}$.

No dia 5 de agosto de 1954, reuniram-se em assembléia geral cerca de 180 pessoas que assinaram a lista de presença, durante a fundação da ABBR, no auditório da Associação Brasileira de Imprensa, no centro do Rio de Janeiro. Fizeram parte da mesa de constituição da ABBR as seguintes pessoas: Paulo César M outinho (representando a Sra. Darcy Vargas, presidente da Legião Brasileira de Assistência), H art E. Van Riper (Diretor da The National Foundation for InfantileParalysis), Cândida VillasBoas Cordeiro (Serviço de Intercâmbio e Civismo da Prefeitura do Distrito Federal), Oswaldo Pinheiro Campos (chefe de cirurgia do Hospital Jesus, membro honorário da Academia Americana de Ortopedia, M embro da Associação Britânica de Ortopedia e membro permanente do Congresso Internacional de Poliomielite), Jorge Faria (médico ortopedista da assistência municipal e do Hospital de Pronto Socorro do Rio de Janeiro), Eunice Pourchet ( professora do Instituto de Educação e organizadora de cursos de terapia ocupacional), Alberto Coutinho (médico clínico), Fernando lehly de Lemos (diretor da Companhia Editora e Comercial F. Lemos), Nilo Colonna dos Santos (engenheiro e diretor presidente da construtora $\mathrm{Ca}$ valcanti Junqueira $S / A$ ), O rmeo Junqueira BoteIho (engenheiro e presidente da Companhia de Força e Luz Cataguazes-Leopoldina) eo jornalista Floresta de Miranda ${ }^{45,46}$.

$\mathrm{Na}$ ata da Assembléia Geral de constituição da ABBR, Fernando Lemos era referido como "0 grande idealizador e incansável batalhador na fundação da Associação Brasilei ra Beneficente de Reabilitação" ${ }^{46}$. Nos registros na ata de fundação da Associação, consta que Fernando Lemos, em seu pronunciamento durante a assembléia expôs "como Ihe veio a idéia de fundar a Associação, diante das dificuldades com que lutou no 
tratamento de seu único filho, vítima da paralisia infantil"46. Oswaldo Pinheiro Campos, por sua vez, ressaltou a grave situação da poliomielite no Rio deJaneiro. Euniche Pourchet, que dirigia cursos de "especialidade dos professores de classes de crianças deficientes" eteria organizado também o "primeiro curso de terapêutica ocupacional" no Brasil, discorreu sobre a formação técnica em reabilitação $0^{46}$. Em seu pronunciamento, o médico Alberto Coutinho, queacompanhou a doença do filho de Fernando Lemos, lembrou das dificuldades que os pais se defrontam no Brasil na recuperação dos filhos atacados pela paralisia infantil. 0 jornalista Floresta de M iranda relatou sobre o drama que viveu quando seu filho foi vítima de poliomielite. 0 engenheiro Ormeo Junqueira também falou do caso de sua filha que foi trazida de Minas Gerais para ser internada com paralisia infantil no Rio de Janeiro "tendo lutado com grandes dificuldades por não existir nenhum estabelecimento especializado onde pudesse fazer a internação" 46 .

Durante a solenidade de fundação da ABBR, antes de se passar à leitura e aprovação do primeiro estatuto da entidade, fez-se uma homenagem "ao heroísmo das incansáveis mães brasileiras, cujos filhos tenham sido vítimas da paralisia infantil"46.

U ma marca comum que unia vários participantes da Assembléia de criação da ABBR era a deficiência física. Estavam ali certamente muitos pais e parentes de crianças vítimas da poliomielite. $O$ primeiro presidente da ABBR, Percy Charles Murray, era portador de deficiência e participava de todas as atividades sociais em uma cadeira de rodas reclinada especialmente adaptada. A questão da poliomielite tinha significado do ponto de vista epidemiológico, social epolítico, mas, sem dúvida, havia um fator de envolvimento pessoal efamiliar com força suficiente para reunir mais de uma centena de pessoas da sociedade carioca em torno da criação da ABBR.

Dentre os objetivos da ABBR, vale ressaltar, em primeiro lugar, a importância da "Iuta contra a paralisia infantil". 0 combate especificamente a esta doença é complementado pela necessidade de reeducar, reabilitar, ou mesmo realizar a "re cuperação físico-moral" de pessoas afetadas também por outras doenças, inclusive por acidentes ${ }^{46}$. 0 objetivo deveria ser reabilitar o portador de algum tipo de deficiência para "reintegrá-lo na vida e na sociedade", para o "reaproveitamento do indivíduo"46. Ainda como objetivos da entidade estavam a criação de uma escola formadora e de um hospital ${ }^{46}$.
Além do idealismo do arquiteto Fernando Lemos, dos conhecimentostécnicose experiência internacional do grupo de médicos reunidos por Oswaldo Pinheiro Campos, havia ainda mais um grupo de extrema importância para que a ABBR e a Escola de Reabilitação do Rio de Janeiro se tornassem realidade: os empresários. Liderados por Percy Charles Murray, faziam parte da diretoria da entidade ou nela colaboravam (como membros do conselho fiscal) grandes empresários do setor de seguros como Celso Rocha M iran$\mathrm{da}$, Carlos Luz (que ocupou interinamente a Presidência da República em 1955) e Ângelo Mário Cerne, assim como empresários de outros segmentos, como Mario Simonsen (dono da TV Excelsior, do Banco Noroeste e outras empresas), Candido Guinle de Paula M achado (empresário do setor editorial, dono do Banco Boavista e de outras empresas) e Herbert M oses (diretor tesoureiro do jornal 0 Globo e presidente da $A B I$ ).

Celso da Rocha Miranda, que foi membro do conselho consultivo da ABBR, era um bemsucedido empresário que atuava no ramo de seguros e também dono da Pan Air do Brasil, uma das principais companhias aéreas do país na épo$\mathrm{Ca}^{47}$. Rocha M iranda tinha forte ligação com 0 presidente Juscelino Kubitscheck, tendo se mudado para São Paulo com o intuito de angariar apoio dos empresários paulistas à campanha eleitoral de JK à presidência ${ }^{47}$. Também fundou $a$ Ajax, uma das maiores empresas de seguro do país, que tinha como sócio Percy Charles Murray. A família M urray teve grande envolvimento com a ABBR, não apenas com Percy como primeiro presidente da entidade, mas também com a participação de seu pai Charles Murray, Sidney e Marisa Murray, esta última como importante voluntária na entidade. A família Murray era dona da Companhia N acional de Comércio de Cafée, entre outras atividades, representava no Brasil a Casa Lazard e Brothers, banqueiros internacionais que faziam grandes empréstimos no país ${ }^{47}$.

A proximidade de JK com Celso Rocha Miranda e outros membros da diretoria da ABBR, além de seu interesse por projetosfilantrópicose sociais, como foi o caso da fundação das Pioneiras Sociais em M inas Gerais (1951), Rio deJaneiro (1956) e Brasília (1960) ${ }^{48}$, facilitaram a aproximação do presidente com a causa da ABBR. No dia 17 de setembro de 1957, o presidente Kubitschek inaugurou o centro de reabilitação da ABBR. Os primeiros pavilhões eram feitos de madeira. Foram " 40 toneladas de madeira fornecidas pela D. Sara Kubitscheck" 49 . 0 terreno ocupado pela ABBR no bairro do Jardim Botâ- 
nico, onde até hoje funciona a instituição, foi doado em 1960 pelo governador interino do Estado da Guanabara, Sette Câmara, aliado político do presidente Juscelino ${ }^{50}$. Neste mesmo terreno, funcionava um local de convalescença das crianças internadas por poliomielite no H ospital Jesus. 0 projeto arquitetônico do centro de reabilitação foi elaborado gratuitamente pelo próprio Fernando Lemos, assim como também diversas empresas cariocas doaram cimento, azulejos, tacos e pisos e transportaram os materiais de obra gratuitamente ${ }^{49}$.

O Correio da M anhã noticiou a inauguração do centro de reabilitação da ABBR: 0 presidente chegou em companhia da senhora Kubitschek e após desatar a fita simbólica, foi saudado pelo Sr. Percy Charles M urray, presidente da ABBR evicepresidente do centro de reabilitação. Em seguida, descerrou a bandeira que envolvia a placa come morativa do ato, tendo percorrido, demoradamente, o setor de fisioterapia e ginástica médica, a sala de terapia ocupacional e as salas de aulas ${ }^{51}$.

Diantedo presidenteda República, do M inistro da SaúdeM aurício de M edeiros edemais convidados, o Sr. Percy Charles Murray, presidente da ABBR, falou sobre a existência de cerca de "um milhão de inválidos, os quais ocupam ou preocupam cem milhões de pessoas" no paí $5^{52}$. Segundo Percy, a ABBR "foi fundada com o objetivo de prestar assistência a esses inválidos, de maneira a torná-los cidadãos normais" ${ }^{52} . \mathrm{Na}$ ocasião, foi apresentado pelo Sr. Robert Sutherland, presidente da Grand Advertising Publicidade S. A., o programa de divulgação da ABBR, que incluía "desfile e passeatas, cartazes, anúncios pela imprensa e o envio de cerca de 30.000 cartas-apelo à população carioca"52.

Uma das grandes preocupações da ABBR nos seus primeiros anos de funcionamento, além da ampliação das suas instalações para melhor atender a centenas de pacientes, era com o custeio de suas atividades (o que persisteatéhoje). N osanos 1950 e 1960, a ABBR sobrevivia graças aos convênios com "institutos, organizações para-estatais, associações e hospitais, firmas industriais e comerciais", com ajuda de "padrinhos" que assumiam o compromisso de custear o tratamento de determinadas crianças, com pagamentos de pacientes que tinham condições financeiras para arcar com o tratamento e, especialmente, graças às campanhas organizadas pelas Legionárias da $A B B R$ isoladamente ou em parceria com outras entidades, como Rotary Club, Lions Club, Câmara Júnior, etc ${ }^{49}$.
As Legionárias da ABBR era um grupo de senhoras da sociedade carioca que trabalhavam voluntariamente para angariar fundos para a entidade. Seu trabalho consistia na organização de eventos sociais e festas, costura de roupas, apadrinhamento de crianças, auxílio nas tarefas administrativas e técnicas do centro de reabilitação, passeios e outras atividades com renda revertida para a entidade. A senhora M alú da Rocha Miranda, esposa do empresário Celso Rocha Miranda, foi presidente das Legionárias, e com o intuito de angariar novas colaboradoras para o trabalho voluntário e garantir doações, coordenava 0 envio de cartas às mães cariocas, com o seguinte texto: Já pensou um só instanteem ter um filho paralítico?

U m filho espástico que com quinze anos pode ter a mentalidade de três? Como somos felizes nós que podemos dormir tranqüilas, nós que não temos preocupação do dia de amanhã, nós que não precisamos levar pela mão ou no colo nosso filho para ir ao colégio. É por tudo isso quetrabal hamos pela ABBR é por isso que pedimos sua ajuda ${ }^{49}$.

Um exemplo de trabalho das Legionárias foi 0 acordo firmado entre a ABBR e o poeta Vinícius de M oraes. Em agosto de 1956, em carta assinada pela Sra. M alu da Rocha M iranda erecebida por Vinícius, as Legionárias assumiam o compromisso de vender cerca de 1.350 lugares do Teatro Municipal para a peça O rfeu da Conceição, de autoria deVinícius deM oraes, dos quais quarenta por cento da renda seriam revertidos para a ABBR ${ }^{53}$. Espetáculos, bailes, passeatas e até campanhas na televisão (antiga TV Rio) fizeram parte das ações de divulgação e arrecadação de receitas para a ampliação e custeio da ABBR.

\section{Formação dosfisioterapeutas}

No cenário internacional, as primeiras escolas formadoras de fisioterapeutas iniciaram suas atividades no final do século XIX einício do sécuIo XX; a partir da Inglaterra (1895) e Alemanha (1902) , novas instituições foram sendo criadas em outros países da Europa, Estados Unidos da América do Norte, Canadá e Austráliaa 18,54-56,9.

$\mathrm{Na}$ América Latina, as primeiras instituições formadoras de fisioterapeutas foram criadas nas décadas de 1940 e 1950. Foi o caso da Colômbia, em 1952 - 53, com a Escola Nacional de Fisioterapia ${ }^{57}$ e do Chile, com a Escola de Fisioterapia da Universidade do Chile ${ }^{58}$, criada em 1956. Na Argentina, um dos primeiros serviços especiali- 
zados, que incluía o treinamento profissional em fisioterapia, foi o Instituto Municipal de Radiologia e Fisioterapia, criado em 1925 em Buenos Aires ${ }^{59,60}$.

As primeiras instituições de ensino a formar fisioterapeutas regularmente no país, antes mesmo da regulamentação da profissão, foram a Escola deReabilitação do Rio de Janeiro, em 1956, o Instituto deReabilitação deSão Paulo, em 1958, e a Faculdade de Ciências M édicas de $M$ inas Gerais (Fundação Arapiara), em 1962 ${ }^{15,17}$. A antiga Escola Nacional de Educação Física e Desportos da Universidade do Brasil - ENEFD (atualmente Escola de Educação Física e Desportos da UFRJ) ea Escola deEducação Física do Exército (ambas no Rio de Janeiro) ofereciam disciplinas defisioterapia na formação de educadores físicos e de médicosespecializados em medicina desportiva ${ }^{61}$. O professor Camilo Abud, catedrático em fisioterapia da ENEFD, ministrou também cursos de "instrução de recuperadores", "treinamento e massagem" e formação em massagem desde a criação da Escola em 193962,63. Os serviços de fisioterapia existentes em diversos hospitais do Rio de Janeiro (Hospital Carlos Chagas, Barata Ribeiro e Santa Casa de M isericórdia) treinavam seus próprios funcionários em serviço ou recebiam os egressos dos cursos ministrados pelo professor Camilo Abud.

Também em São Paulo, existia a formação em serviço detécnicos para trabalharem em hospitais. Um exemplo deste tipo de formação foi 0 curso "Raphael de Barros"12, oferecido no início dos anos 1950. O objetivo da formação era capacitar profissionais auxiliares médicos chamados de "técnicos operadores em fisioterapia", em um curso com um ano de duração ${ }^{12}$. A formação era uma exigência para todos que trabalhavam no serviço de fisioterapia do Hospital das Clínicas da Faculdade de M edicina da Universidade de São Paulo - USP ${ }^{19}$. Este curso teveinício em 1951 e encerrou suas atividades em $1956^{18}$.

O curso regular do Instituto de Reabilitação em São Paulo (ligado à USP) iniciou sua primeira turma em 1958. Deacordo com Robin F. Hindley-Smith, médico consultor da Organização Mundial de Saúde (OMS), e um dos responsáveis pelo curso do INAR, a primeira turma de técnicos em fisioterapia graduou-se no final de 1959, após a conclusão de um curso regular de dois anos de duração ${ }^{64}$.

De acordo com o Departamento de Assuntos Econômicos e Sociais das Nações Unidas, foi estabelecida cooperação internacional com a USP para a criação do Instituto de Reabilitação (INAR). As N ações Unidas participaram do planejamento geral , próteses efisioterapia; a Oficina Internacional do Trabalho (OIT) participou da orientação profissional e recolocação para o trabalho; e a Organização M undial da Saúdetomou partecom a medicina física e coordenação de programas. 0 projeto era tornar o INAR um modelo de reabilitação para outros países da América Latina. De acordo com o relatório das Nações Unidas ${ }^{72}$ sobre a formação dos fisioterapeutas, no INAR eram oferecidos cursos com dois anos de duração. Segundo o mesmo relatório, a Escola de Reabilitação do Rio de Janeiro já havia instituído anteriormente um "programa especial para a formação de fisioterapeutas", baseado em um plano de estudos de três anos ${ }^{65}$.

Embora o objetivo deste artigo não seja realizar uma comparação entre os cursos regulares de formação do INAR e da ERRJ, é importante destacar resumidamente algumas diferenças. 0 curso oferecido pelo INAR, a partir de 1958, tinha como pré-requisito para ingresso o segundo grau (ensino médio) ou antigo colegial. Logo após o reconhecimento doscursos daERRJ (1965), a USP publicou uma portaria definindo que o Instituto de Reabilitação "ministra cursos normais de graduação em Fisioterapia eTerapia O cupacional"66, ao que acrescentou em 1970, por meio da Portaria $n^{\circ} 1.025$ de 16 dejaneiro de 1970, o reconhecimento dos certificados emitidos pelo INAR nos cursos de técnicos em Fisioterapia e em Terapia Ocupacional entre os anos de 1958 a 1966 como equivalentes ao de nível superior da U SP14.

A formação no INAR seguia os parâmetros do Comitê de Reabilitação M édica da OMS, do qual fazia parte o Dr. Godoy Moreira, professor de ortopedia e traumatologia do Hospital das Clínicas da USP. Para a OMS, a "formação de fisioterapeutas nos países menos desenvolvidos deveria ser necessariamente rápida, especialmente na parteteórica, por conta da fal ta de professores capacitados"67. De forma diferente, a formação na ERRJ, além de não ter sido realizada dentro deuma instituição pública como em São Paulo, não teve seu currículo definido pela OMS, foi iniciada como de nível superior desde o início e inspirada nos currículos de países desenvolvidos da América do Norte e Europa, com duração de três anos. 
A formação
na Escola de Reabilitação do Rio de Janeiro

A Diretoria da ABBR, embora pretendesse rapidamente criar o centro de reabilitação da entidade, foi desencorajada por seu conselho técnico. Inicialmentefizeram partedesteconselho os médicos Oswaldo Pinheiro Campos, Jorge Faria, Antonio Caio do Amaral e Hilton Baptista. A proposta, aceita pela diretoria, era que antes de se criar um centro de reabilitação, era preciso formar os profissionais que ali iriam trabalhar: fisioterapeutas e terapeutas ocupacionais ${ }^{68}$.

Em reunião realizada no dia 23 de setembro de 1955, na residência de O swaldo Pinheiro Campos, "foram estabelecidos os planos básicos para o funcionamento daEscola"68. Fizeram partedesta reunião Fernando Lemos e José M aria de Almeida, como representantes da diretoria da ABBR, e os seguintes professores fundadores: Oswaldo Pinheiro Campos, Jorge Faria, Antonio Caio do Amaral, Hilton Baptista, Pedro $\mathrm{N}$ ava, Antonio Rodrigues de M ello, Zeny M iranda, Alcino Alfonseca J r., Edmundo H aas, Pedro Baptista de O liveira N eto, Gualter Doyle Ferreira, Evangelina Leivas, Edith Mc Connell, Mary Ellis e D ora Schlochauer ${ }^{68}$.

$\mathrm{N}$ a mesma noite da reunião do dia 23 de setembro, foi designado o Dr. Jorge Faria para instalar edirigir a Escola de Reabilitação. 0 currículo utilizado como base para a escola, segundo Hilton Baptista, foi o da "Escola de Reabilitação da Columbia University"68.

A formação dos fisioterapeutas acontecia em salas de aula construídas dentro da própria ABBR einicialmente os alunos também se deslocavam para outras instituições, como a Policlínica do Rio de Janeiro, Hospital Carlos Chagas, H ospital Getúlio Vargas, Hospital Jesus, H ospital Pedro Ernesto e Cruz Vermelha ${ }^{11}$.

Os cursos de graduação em fisioterapia e terapia ocupacional iniciaram suas atividades no dia 3 de abril de 1956. A sessão solene de instalação dos cursos foi realizada no auditório da Associação Brasileira de Imprensa ( $A B I)$, às 21 horas. Assinaram o "Livro de Presença às Solenidades" setenta e cinco pessoas, entre alunos da primeira turma, professores, diretores da ABBR, médicos ligados à reabilitação e representantes da Policlínica do Rio de Janeiro, do Rotary Club, da Associação Brasileira de Prevenção deAcidentes, da Associação de Pais e Amigos dos Excepcionais (APAE) eSociedade Pestalozzi ${ }^{69}$.

Segundo Hilton Baptista, a sessão solene de instalação dos cursos foi presidida pelo presi- dente da ABBR, Percy Charles Murray, e a ela compareceram também o representanteda $\mathrm{ONU}$, membros do corpo diplomático, representantes dos ministérios da Educação e do Trabalho, Le gionárias da ABBR e o presidente da Sociedade Brasileira de M edicina Física e Reabilitação. “Estava fundada a primeira Escola de Reabilitação do Brasil" 68 .

A Escola de Reabilitação da ABBR possuía dois cursos regulares: fisioterapia e terapia ocupacional. Antonio Caio do Amaral, vice-diretor da ERRJ, ao referir-se à formação dos fisioterapeutas e dos terapeutas ocupacionais, ressalta que "nossa Escola procura, principalmente, formar duas especialidades dentro do quadro geral da Reabilitação"70.

De acordo com o Regimento Interno da Escola de Reabilitação da ABBR, a ERRJ deveria ser uma escola de caráter beneficente, filantrópico e sem finalidade lucrativa, tendo como finalidade, dentre outras, a de "preparar candidatos ao exercício das profissões de fisioterapeutas e terapeutas ocupacionais" ${ }^{\prime 1}$. Em seu artigo sétimo, o regimento interno define o curso de bacharelado em fisioterapia com duração de três anos, tendo por objetivo "formar profissionais em fisioterapia, denominados fisioterapeutas" 71 . No mesmo artigo, define que estes profissionais devem ser dotados dos conhecimentos necessários à compreensão, investigação e interpretação das causas e dos efeitos biológicos da fisioterapia como agente colaborador, para dar ao lesionado o máximo de sua capacidade residual, com competência para sugerir modificações nas dosagens dos diferentes agentes físicos utilizados, e com a faculdade para compreender o sentido social da especialidade e 0 seu papel na reabilitação evalorização do homem ${ }^{71}$.

De acordo com o regimento, as disciplinas consideradas como fundamentais e as disciplinas clínicas especializadas a serem oferecidas no primeiro ano do curso eram: anatomia descritiva, cinesiologia clínica, massoterapia, termoterapia, patologia médica, psicologia aplicada à reabilitação, fundamentos da reabilitação, clínica ortopédica e clínica traumatológica. Na parte da tarde, eram ministradas as disciplinas e, na parte da manhã, eram realizados os trabalhos práticos dos alunos no Centro de reabilitação. A freqüência dos alunos no centro de reabilitação desde o primeiro ano do curso era obrigatória, com a finalidade de "pôr os alunos em contato com os pacientes" 80 . No centro de reabilitação, os alunos eram "iniciados na prática de exame dos pacientes, na aplicação da fisioterapia, massoterapia, etc..." ${ }^{71}$. 
No segundo ano do curso, as disciplinas fundamentais e clínicas especializadas eram: anatomia descritiva, fisiologia humana, cinesiologia clínica, cinesioterapia, hidrobalneoterapia, crenoclimatoterapia, psicopatologia, clínica médica, clínica neurológica, clínica reumatológica eclínica psicossomática. No segundo ano, eram "intensificados os trabalhos práticos no Centro de Reabilitação iniciados no primeiro ano letivo", e no terceiro ano a característica principal éo "estágio obrigatório e intensivo" realizado no centro de reabilitação da $\mathrm{ABBR}^{71}$.

0 regimento previa ainda a oferta de disciplinas e atividades supletivas com a finalidade de "completar o aperfeiçoamento do aluno", como, por exemplo, as disciplinas deinglês, educação física, assistência social, enfermagem, foniatria e dicção, mímica e clínicas especializadas supletivas ${ }^{71}$.

0 ingresso dos primeiros alunos na ERRJ foi feito através de prova, sendo oferecidas um total de trinta vagas para fisioterapia e terapia ocupacional. Para ingressar no curso, era exigido dos alunos a conclusão do ensino médio (científico, normal ou clássico) ou ainda dos cursos de enfermagem, educação física ou de serviço social ${ }^{11}$. Dos 23 profissionais formados pela primeira turma em 1958 (dezesseis fisioterapeutas eseteterapeutas ocupacionais), quinze foram contratados para trabalhar imediatamente no próprio centro de reabilitação da $A B B R^{11}$.

Em média, o número de fisioterapeutas formados de 1958 a 1970 foi de pouco mais de treze em cada turma, somando um total de 175 fisioterapeutas egressos da ERRJ neste período. De 1971 até 1980, a média passou para pouco mais de 33 fisioterapeutas formados por cada turma, somando 366 fisioterapeutas egressos neste período na ERRJ (dados obtidos durante pesquisa no acervo pessoal da Sra. M aria Antônia Pedrosa Campos, ex-secretária da ERRJ). 0 aumento do número de egressos coincide com a regulamentação da profissão em 1969, indicando provavelmente uma maior procura pela formação e menor evasão de alunos após seu reconhecimento oficial pelo Estado brasileiro.

\section{O reconhecimento da ERRJ}

Ao concluinte do curso de graduação em Fisioterapia deveria ser concedido o diploma de bacharel em fisioterapia, quehabilita o portador a exercer a profissão de fisioterapeuta, sendo que o direito ao exercício da profissão somente será váli- do "após o registro do título na repartição competente do M inistério da Educação e Cultura"71.

À medida que se formavam novas turmas, aumentava também a pressão por parte dos egressos com relação ao registro de diplomas e ao exercício da profissão de fisioterapeuta. A ABBR começou então a empreender esforços tanto para o reconhecimento das profissões, apoiando dois projetos de lei apresentados no Congresso Nacional, quanto para o próprio reconhecimento da Escola, por intermédio de processo administrativo aberto no Conselho Nacional de Educação com vistas ao reconhecimento dos cursos pelo MEC.

0 projeto delei $n^{\circ} 4.789$ de 1958 , apresentado pelo deputado Portugal Tavares, regulamentava a formação de fisioterapeutas, terapeutas ocupacionais e de licenciados em reabilitação ${ }^{2}$. 0 projeto, encaminhado às Comissões de Constituição e Justiça e de Educação e Cultura, era praticamente uma cópia resumida, muitas vezes sem alterar uma vírgula sequer, do regimento interno da ERRJ. 0 projeto definia que fisioterapeutas deveriam ser formados em escolas de reabilitação, com duração de curso de três anos.

$\mathrm{Na} \mathrm{justificativa} \mathrm{apresentada} \mathrm{junto} \mathrm{ao} \mathrm{projeto,}$ o deputado Portugal Tavares declara que, a exemplo do que ocorria em países como Estados Unidos da América do Norte, Inglaterra, Canadá e Israel, existia no Rio de Janeiro (Distrito Federal), "em pleno funcionamento, Escola de Reabilitação cujo Centro atende cerca de 100 pacientes por mês"2. Sobre os cursos de formação ministrados, o deputado autor do projeto lembra que os mesmos foram iniciados em abril de 1956, "após terem sido instalados em sessão solene real izada na $A B I$, na presença de gradas personalidades" 2 . Segundo o autor do projeto, o início dos cursos era imprescindível, pois"os técnicos disponíveis eram contratados no estrangeiro e, faceà grande procura de seus serviços, tornaram-se exíguos"2. Ao concluir a justificativa do projeto de lei em questão, 0 deputado afirma que esta proposição visa "oficializar uma Escola que, no país, tem similar apenas no Instituto de Reabilitação de São Paulo"2.

0 projeto em pauta, após ser aprovado na Comissão de Educação do Congresso Nacional, foi encaminhado à Comissão de Saúde, onde foi produzido um texto substitutivo ao projeto original, que, submetido à ABBR e ao Instituto de Reabilitação deSão Paulo, foi rejeitado pelas duas instituições em razão de "não corresponder às determinações internacionais para a formação de técnicos dessa natureza"3. D evido a esta rejeição, o projeto foi arquivado. 
Em 1963, um novo projeto de lei, de autoria do Deputado João Vieira, tinha por objetivo regulamentar a formação de fisioterapeutas eterapeutas ocupacionais. Este projeto trazia al gumas poucas diferenças para o projeto anterior, dentre elas, a inclusão de um artigo que definia uma carga horária mínima de formação de 2.500 horas, sendo 1.000 horas de aulas teórico-práticase 1.500 horas de treinamento (estágio). Em seu artigo treze, determinava que "as atividades dos fisioterapeutas e dos terapeutas ocupacionais somente poderão ser exercidas sob orientação e responsabilidade médica" ${ }^{3}$.

Na justificativa do projeto, o Deputado João Veiga declara que o projeto em análise é fruto de um profundo estudo dos técnicos da ABBR e do INAR. Ao concluir a justificativa, acrescenta 0 seguinte: "E quem tem a felicidade de ter filhos sadios, tem obrigação de dar alguma coisa para a causa da reabilitação, esse é 0 lema da ABBR"3. Em março de 1967, esta iniciativa também foi arquivada.

Diante das dificuldades em aprovar uma lei que regulamentasse a formação dos fisioterapeutas através do Congresso $\mathrm{N}$ acional, restava ainda mais uma alternativa, a via administrativa, através do Conselho Nacional de Educação (CNE).

Em 1961, foi instituída pela direção da ERRJ uma comissão responsável por preparar a documentação necessária e acompanhar o processo de reconhecimento dos cursos no Ministério da Educação. N este momento, já havia, além do próprio desejo institucional, uma forte mobilização dos estudantes e egressos dos cursos com o objetivo de validar seus diplomas. A comissão foi formada pela secretária da ERRJ, M aria Antonia Pedrosa Campos, a terapeuta ocupacional formada pela primeira turma, $\mathrm{H}$ ilêde Wanderley Catanhede, e o médico Artur de Pádua Viana ${ }^{12}$.

Por meio do processo no 97.990 de 1961, a ABBR solicitou ao Conselho Nacional de Educação o reconhecimento dos cursos da Escola de Reabilitação do Rio de Janeiro72. 0 parecer da Câmara deEnsino Superior do Consel ho N acional de Educação, n 602 de 1961, declara que os cursos oferecidos pela ERRJ possuem "altos coeficientes deutilidade social a ponto deatenderem a inadiáveis interesses comunitários", e acrescenta ainda que possuem uma "auréola de benevolência" reconhecida pela opinião pública ${ }^{73}$. A conclusão do parecer éque seja encaminhado o processo "no sentido do reconhecimento e não mais da simples autorização para funcionar", como havia acontecido com outros pareceres ${ }^{73}$.

Em dezembro de 1961, com a primeira Lei de
Diretrizes e Bases da Educação, houve mudanças significativas no sistema educacional brasileiro, incluindo a extinção do Conselho $\mathrm{N}$ acional de Educação ea entrada em funcionamento do Conselho Federal de Educação, já em $1962^{74}$. Em vista do Parecer $n^{\circ} 602 / 61$, foram realizadas numerosas verificações com base nas quais o novo Conselho Federal de Educação opinou, através do Parecer $n^{\circ} 362 / 63$, pela necessidade de estabelecimento de um currículo mínimo e tempo de duração dos cursos de formação em questão. De acordo com o parecer, a ERRJ deveria proceder à adaptação do seu regimento à Lei de Diretrizes e Bases da Educação (LDB) 75 .

0 relator deste parecer, quefoi o médico e exministro da Educação e Cultura Clóvis Sal gado, ressaltava em seu texto que, em 1961, a Escola havia solicitado inicialmente o reconhecimento dos seus cursos, e que "sobre a matéria há pronunciamento do extinto $\mathrm{CNE}$, opinando pela criação dos cursos através de lei"75. N o entanto, ao longo detrês páginas, o relator conclui que, "sem forçar a interpretação, o fisioterapeuta e o terapeuta ocupacional que a A.B.B.R. pretende formar são modalidades de enfermagem", e acrescenta ainda que, "poder-se iam incluir entre os cursos de enfermagem, mais dois novos, tendo em vista os interesses da reabilitação"75. Ao Iongo do texto, é possível perceber diversas referências aos médicos, normalmente ressaltando que "trata-se de formar um profissional para-médico", que fisioterapia e enfermagem são profissões que "executam prescrições médicas" eainda que o conceito de profissão "seria aquela exercida pelo médico, com plena responsabilidade por todos os atos", sendo enfermagem e fisioterapia "meras ocupações"

H avia uma clara preocupação de que o reconhecimento dos cursos de fisioterapia e de terapia ocupacional, e mais especialmente o primeiro, não interferisse no controle dos médicos sobre as demais profissões da área de saúde. Tal hipótese parece ganhar mais força ao ser analisado um outro parecer (388/63), também relatado por Clóvis Salgado, com base no qual foram definidos os currículos mínimos para os cursos de fisioterapia e de terapia ocupacional.

$\mathrm{Na}$ justificativa do Parecer $\mathrm{n}^{\circ} 388$, o relator afirmava que insiste na caracterização desses profissionais como auxiliares médicos que desempenham tarefas de caráter terapêutico sob a orientação e responsabilidade do médico. A este caberia dirigir, chefiar e liderar a equipe de reabilitação dentro da qual são elementos básicos: o médico, 0 assistente social, o psicólogo, o fisioterapeuta e o 
terapeuta ocupacional ${ }^{76}$ Acrescentando ainda que “Não compete aos doisúltimos o diagnóstico da doença ou da deficiência a ser corrigida. CabeIhes executar, com perfeição, aquelas técnicas, aprendizagens e exercícios recomendados pelo médico"76.

0 texto original do Parecer $n^{\circ} 388 / 63$, produzido pela Comissão eque foi ao Plenário do Conselho Federal de Educação, possuía a seguinte redação em seu quarto parágrafo, com relação ao nome dos profissionais: "[...] não há como evitar os nomes de fisioterapeutas e terapeutas ocupacionais, embora tais denominaç̃oes pudessem sugerir competências e atribuições que são da alçada dos formados em medicina [...]"72. No entanto, durante sua passagem pelo Plenário do Consel ho Federal deEducação, o Parecer tevesua redação alterada, modificando seu conteúdo original para: "[...] não há como evitar os nomes de Técnicos em Fisioterapia e Técnicos em Terapia Ocupacional" 76 .

Outra alteração no parecer original da comissão, realizada em plenário, foi com relação às matérias comuns definidas no currículo mínimo. Segundo o texto original, seriam disciplinas comuns aos cursos de fisioterapia e de terapia ocupacional: física, anatomia, fisiologia, psicologia, cinesiologia, patologia geral, ética e história da reabilitação, e administração $0^{72}$. Em plenário, as seis primeiras disci plinas foram reduzidas para somente uma: fundamentos da fisioterapia e da terapia ocupacional e a matéria de administração passou a chamar-se administração aplicada $^{76 .}$ E concluindo o parecer, ao opinar sobre o currículo praticado pela ABBR, a comissão entendeu ser este excessivo, "preferindo esquema bem mais modesto e exeqüível, como convém ao meio brasileiro"76.

A comparação entre o texto original do parecer apresentado pela comissão e o texto aprovado em plenário revela significativas alterações e parece sugerir que o plenário do CNE teria tornado o Parecer $n^{\circ} 388 / 63$ ainda mais restritivo com relação à formação que vinha sendo oferecida aos estudantes de fisioterapia na ERRJ.

Em 23 dejulho de 1964, o M inistério da Educação definiu, pela primeira vez, o currículo mínimo dos cursos de fisioterapia e de terapia ocupacional, baseando-se no Parecer $n^{\circ} 388 / 63$. A duração dos cursos foi definida em três anos letivos e as matérias comuns aos cursos de Fisioterapia e de Terapia O cupacional eram fundamentos de fisioterapia e terapia ocupacional, ética e história da reabilitação, e administração aplicada, como matérias específicas de Fisioterapia fo- ram estabelecidas fisioterapia geral e fisioterapia aplicada ${ }^{76}$.

Uma vez publicado o currículo mínimo pelo $M E C$, restava à $A B B R$ fazer as adequações em seu regimento ecurrículo, acrescentando ao processo original de reconhecimento dos cursos no Conselho Federal de Educação. Estas e outras providências solicitadas pelo relator Clóvis Salgado foram atendidas pela ERRJ.

Somenteno mês dejulho de 1965, o Parecer $n^{\circ}$ 715/65 da Câmara de Ensino Superior realizou a análise das adaptações apresentadas pela ERRJ e se manifestou favorável ao reconhecimento da Escola de Reabilitação ${ }^{77}$. A solução encontrada pela ABBR para adequar-se ao currículo mínimo estabelecido pelo MEC consistiu em agrupar as disciplinas existentes de anatomia, fisiologia, cinesiologia, patologia geral, psicologia efísica aplicada à reabilitação, mantendo todos os seus professores e carga horária, em uma grande disciplina chamada fundamentos de fisioterapia e de terapia ocupacional. Além da disciplina de fisioterapia geral, prevista no currículo do M EC, a disciplina defisioterapia aplicada foi multiplicada em sete novas disciplinas, fisioterapia aplicada à reumatologia, fisioterapia aplicada à ortopedia, fisioterapia aplicada à traumatologia, fisioterapia aplicada à neurologia, fisioterapia aplicada à clinica médica, fisioterapia aplicada à clínica cirúrgica e fisioterapia aplicada à psiquiatria. Além destas, foi acrescentada a disciplina de foniatria ${ }^{78}$.

$\mathrm{Na}$ conclusão do parecer sobre o funcionamento da Escola de Reabilitação, os consel heiros do CFE salientaram "o caráter elevadamente meritório de uma associação que mantém tão elevados padrões de ensino e de aplicação técnica no seu Centro de Reabilitação"78. No dia 26 de novembro de 1965, o Presidente Castello Branco, atendendo a solicitação do CFE por meio do Parecer $n^{0} 715 / 65$, concedeu o reconhecimento oficial à Escola de Reabilitação do Rio deJaneiro, pertencenteàABBR, por meio do Decreto $n^{0} 57.363^{23}$.

U ma vez reconhecidos os cursos de fisioterapia e de terapia ocupacional, os primeiros diplomas foram expedidos pela ABBR em 1966. Embora o Parecer $n^{\circ} 388 / 63$ houvesse determinado, em sua versão aprovada em plenário, que os egressos deveriam chamar-se detécnicos em fisioterapia, a ABBR não utilizou esta nomenclatura em nenhum de seus diplomas, constando do documento apenas a formação no curso de fisioterapia.

Em 1969, com a publicação do Decreto-lei no 938 quereconheceu oficial menteas profissões de fisioterapeuta edeterapeuta ocupacional no país, parecia finalmente superada a questão da deno- 
minação das profissões e de sua relação com outras profissões da área de saúde, especialmente a medicina. 0 decreto definiu como privativa do fisioterapeuta a atuação na área de fisioterapia e o habilitou oficialmente, como profissional liberal, a dirigir serviços em órgãos ou estabelecimentos públicos e privados, além de exercer 0 magistério nas disciplinas de formação básica el ou profissional ${ }^{1}$.

Um mês após a promulgação do Decreto-lei no 938/69, a Comissão de Saúde do Congresso $\mathrm{N}$ acional, formada por médicos, aprovou por unanimidade, o projeto delei $n^{\circ} 2.090$, deautoria da própria Comissão, que tinha por objetivo alterar o texto do Decreto-lei $n^{0} 938^{79}$. De acordo com o texto do projeto, ao invés da palavra fisioterapeuta, o decreto-lei deveria se referir a "técnico em fisioterapia", ficando também totalmente proibido a estes profissionais atender a qualquer paciente sem supervisão médica e que não tenha sido enviado por médico, promover anúncio ou publicidade sobre sua atividade e até mesmo proibido instalar consultório. Este projeto foi derrotado em votação no Congresso Nacional e arquivado em maio de $1972^{79}$.

\section{Conclusão}

A fundação da ABBR no Rio de Janeiro representou uma resposta original da sociedade cariocaà epidemia depoliomielitevigentena cidadee no país. 0 impacto da deficiência física na sociedade (afetando diferentes classes sociais), o forte apelo emocional da doença, a capacidade de mobilização social através do voluntariado, da filantropia, do empresariado local, o apoio de governantes, as soluções adotadas por outros países aumentando a presença de fisioterapeutas, juntamente com a capacidade e experiência técnica de al guns profissionais médicos no cenário internacional da reabilitação constituíram um ambiente favorável à criação da ABBR e da primeira escola de reabilitação no país.

As epidemias de poliomielite tiveram, portanto, papel central na criação da primeira instituição formadora de fisioterapeutas no país (ERRJ), assim como influenciaram fortemente no perfil dos primeirosfisioterapeutas como profissionais voltados para a atuação na reabilitação, formados para atender principalmente ao deficiente físico eoutros lesionados.
Uma questão importanteno debate histórico sobre a profissionalização da fisioterapia é a disputa quanto ao perfil do profissional que estava sendo formado para a atuação na área. As controvérsias ocorreram com relação à denominação da profissão e seu nível de autonomia no tratamento dos pacientes e na relação com outras categorias profissionais da saúde, especialmentea medicina. 0 projeto inicial deformação implantado pela OM S em São Paulo e a formação realizada pela ERRJ apontavam para caminhos diferentes na constituição da profissão de fisioterapeuta no país.

A indefinição com relação ao nome da categoria profissional não foi mera formalidade burocrática, mas representava, entre outros aspectos, as disputas e atritos por espaço no mercado de trabalho, interesses relacionados à hierarquização das profissões, reconhecimento social, reconhecimento entre os próprios pares, autonomia ou subordinação da categoria e participação ou exclusão na produção dos conhecimentos científicos.

0 processo de criação e reconhecimento dos cursos da Escola de Reabilitação do Rio de Janeiro se confunde com a organização e luta dos fisioterapeutas em busca deuma identidade própria, de reconhecimento social e legal da profissão nos anos 1960. A ABBR, para além de sua extrema relevância social no atendimento à população carioca, teve papel determinanteno processo de profissionalização da fisioterapia brasileira.

0 movimento em torno do reconhecimento dos cursos da Escola de Reabilitação do Rio de Janeiro parece ter sido um dos grandes responsáveis por "pavimentar" o caminho para o reconhecimento da profissão defisioterapeuta no país.

\section{Agradecimentos}

A gradeço a Superintendência Executiva daABBR, equipe de pesquisa, corpo clínico ecentro deestudos da instituição, especialmente à Ana Rosa Rodrigues, Ana Cristina Franzoi e Rita Figueiredo. Agradecimentos à Coordenadora do Programa de Pós-Graduação em História das Ciências e da Saúde da Casa de Oswaldo Cruz/FIOCRUZ, M aria Rachel Fróes da Fonseca, e ao meu orientador de pesquisa de doutorado, professor Gilberto H ochman. Agradecimento especial à M aria Antônia Pedrosa Campos pela generosidade em permitir a pesquisa em seu acervo pessoal. 


\section{Referências}

1. Brasil. Decreto-lei n 938. Provê sobre as profissões de fisioterapeuta e terapeuta ocupacional, e dá outras providências. Diário Oficial da União 1969; 13 out.

2. Brasil. Câmara dos Deputados. Projeto de lei no 4.789 . Diário do Congresso Nacional 1958, 24 dez. [seção 1 página 8.627 coluna 4]

3. Brasil. Câmara dos Deputados. Projeto de lei no 4.789 . Diário do Congresso Nacional 1958, 24 dez. [seção 1 página 8.627 coluna 4]

4. Brasil. Câmara dos Deputados. Projeto de lei n 3.768 Diário do Congresso Nacional 1966, 29 jun. [seção 1 página 4.216 coluna 1]

5. Brasil. Câmara dos Deputados. Projeto de lei no 1.265 . Diário do Congresso Nacional 1968, 7 ma. [seção 1 página 2.098 coluna 1]

6. Rebelatto JR. 0 objeto de trabalho em fisioterapia e perspectivas de atuação e de ensino nesse campo profissional [dissertação]. São Carlos (SP): Universidade Federal de São Carlos; 1986.

7. Rebelatto JR, Botomé SP. Fisioterapia no Brasil. São Paulo: Manole; 1999.

8. Nicida DP. A interdisciplinaridade como um caminho para a formação do fisioterapeuta [dissertação]. São Paulos (SP): Universidade Cidade de São Paulo; 2002.

9. Barros FMB. A formação do fisioterapeuta na UFRJ e a profissionalização da fisioterapia [dissertação]. Rio de Janeiro (RJ): Instituto de M edicina Social/U niversidade do Estado do Rio de Janeiro; 2002.

10. Galvão AM F. Brasil, a fisioterapia e o tempo. FisioBrasil 2000; 38.

11. Figueirôa RM. Aspectos da evolução histórica do fisioterapeuta no Brasil em especial no Rio de Janeiro [monografia]. Rio de Janeiro (RJ): Instituto Brasileiro de M edicina de Reabilitação; 1996.

12. Define DV, Feltrin MIZ. A Fisioterapia no Brasil. Atualização Brasileira de Fisioterapia 1986; 3(4).

13. Oliveira VRC. Reconstruindo a história da fisioterapia no mundo. Revista Estudos 2005; 32(4): 509-534.

14. Marques AP, Sanchez EL. Origem e evolução da fisioterapia: aspectos históricos e legais. Revista de Fisioterapia da Universidade de São Paulo 1994; 1(1):5-10.

15. Nascimento MC, Sampaio RF, Salmela JH, Figueiredo I. A profissionalização da fisioterapia em $M$ inas Gerais. Revista Brasileira de Fisioterapia 2006; 10(2).

16. Barros FBM. Autonomia Profissional do Fisioterapeuta ao longo da história. Revista FisioBrasil 2003; 59:20-31.

17. Sanchez EL. Estudo preliminar do adestramento de fisioterapeutas no Brasil. Revista Paulista de Hospitais 1971; 19(4)

18. Sanchez EL. Histórico da Fisioterapia no Brasil e no mundo. Atualização Brasileira deFisioterapia 1984; $1(3)$.

19. Oliveira VRC. A história dos currículos de fisioterapia: a construção de uma identidade profissional [dissertação]. Goiânia (GO): Universidade Católica de Goiás; 2002.

20. Nascimento MC. A profissão de fisioterapia em M inas Geras: uma história oral de suas raízes [dissertação]. Belo H orizonte (M G): Universidade Federal de M inas Gerais; 2004.
21. Reis MCS. A formação do fisioterapeuta numa instituição pioneira: a Escola de Reabilitação do Rio de Janeiro (1956-1976) [dissertação]. Petrópolis (RJ): Universidade Católica de Petrópolis; 2004.

22. Soares LBT. Terapia ocupacional: lógica do capital ou do trabalho. Retrospectiva histórica da profissão no Estado brasileiro de 1950 a 1980 [dissertação]. São CarIos (SP): Universidade Federal de São Carlos; 1987.

23. Brasil. Decreto $n^{\circ} 57.363$. Concede reconhecimento à Escola de Reabilitação do Rio de Janeiro da Associação Brasileira Beneficente de Reabilitação. Diário Oficial da União 1965; 2 dez.

24. Gould T. A summer plague: polio and its survivors. New York: Yale University Press; 1995.

25. Neumann D. Polio: Its impact on the people of the United States and emerging professionof Physical Therapy. J Orthop Sports Phys Ther 2004; 34(8):481.

26. Nascimento DR, M aranhão EP. Uma gota, duas doses: criança sadia, sem paralisia. In: Nascimento DR, Carvalho DM, organizadoras. U ma história brasileira das doenças. $1^{\mathrm{a}}$ ed. Braślia: Paralelo 15; 2004. p. 229-241.

27. O Connor B. National Foundation for Infantile Paralysis. Physiotherapy Review 1945; 25:79.

28. Raymond CA. Polio survivors spurred rehabilitation advances. JAM A 1986; 255(11).

29. Neumann D. Polio: its impact on the people of the United States and emerging profession of Physical Therapy. J Orthop Sports Phys Ther 2004; 34(8):481.

30. Maturana A, Badillo AA, M iangolarra-Page JC, Rodriguez-Rodriguez LP. Influencia de las epidemias de poliomielitis sobre la rehabilitación en Espana (1949-1969). Rehabilitacion 2002; 36(1):42-49.

31. Kranz KDC. The public bootstrapping of physical therapy to a provider profession, 1919-86. Chiropractic History 1986; 6:39-48.

32. WCPT. The Early Years - 50's \& 60's. [acessado 2007 dez 20]. Disponível em: http://www.wcpt.org/about/ history/achievements.php

33. Agersnap R. Opportunities for professional growth through recruitment and training. The Physical Therapy Review 1960; 41(5).

34. Lamm G. The World Health Organization's contributions of advancement of rehabilitacion. Biblthca cardiol. 1986; 40:8-19.

35. Peat M. The establishment of physical therapy in developing countries. Progress in Physical Therapy 1970; 1(3):236.

36. United Nations Children's Fund. UNICEF helps rehabilitate physically handicaped children in ten countries. The Physical therapy review 1960; 40(4):292-294.

37. Naciones Unidas. Departamento de assuntos econômicos y sociales de las $\mathrm{N}$ aciones Unidas. Estudio de los aspectos legislativos y administrativos de los programas de rehabilitación de personas impedidas en determinados paises. Nueva York: ONU; 1965.

38. OMS. Comite de Expertos em Rehabilitación M edica - Primer Informe. Genebra: OMS; 1958. [Serie de informes técnicos n. 158]

39. Nogueira RP, Risi JB. As condições de saúde no Brasil. In: Finkelman J, organizador. Caminhos da Saúde Pública no Brasil. Rio de Janeiro: Fiocruz; 2002. p. 119-234. 
40. A sombra da invalidez sobre uma coletividade. Correio da M anhã 1953 Abr 2; p. 3.

41. Campos ALV, Nascimento DR, M aranhão E. A história da poliomielite no Brasil e seu controle por imunização. Hist. cienc. saúde 2003; 10 (Supl 2): 573-600.

42. Paralisia Infantil. Correio da M anhã 1953 Abr 2; p. 4.

43. Primeiro Centro de Reabilitação das Vítimas de Paralisia Infantil. O Globo 1956 Abr 9; p. 11.

44. Associação Brasileira Beneficente de Recuperação. O Globo 1954 Ago 4; p. 7.

45. Campanha contra a paralisia infantil. Tribuna da Imprensa 1954 Ago 3.

46. ABBR. Ata da Assembléia Geral de Constituição da Associação Brasileira Beneficente de Reabilitação (1956). Cartório Civil de Pessoa Jurídica, Rio de Janeiro.

47. CPDOC-FGV. A Atividade de Seguros no Brasil. [entrevista a Plácido da Rocha Miranda, 1998].

48. Fundação das Pioneiras Sociais. Ontem e hoje, 19511991. Lorencina Penolazzi da Silva Pereira. Fundação das Pioneiras Sociais, Delegacia de Minas Gerais, dezembro de 1990 .

49. ABBR. Catálogo de apresentação da ABBR. Rio de Janeiro: Centro de Estudos da ABBR; 1963.

50. Brasil. Governo do Estado da Guanabara. Lei no 18 de 1960.

51. Centro de Reabilitação da ABBR. Inauguração ontem com a presença do Presidente da República e da senhora Kubitschek. Correio da M anhã 1957 Set $18 ;$ p. 8.

52. Inaugurado Centro da Associação Brasileira de Reabilitação. Tribuna da Imprensa 1957 Set 18; p. 6.

53. Carta ABBR - Vinicius de M oraes. Acervo Vinicius de M oraes, 27 de agosto de 1956. Casa de Rui Barbosa.

54. Miles-Tapping C. Sponsorship and sacrifice in the historical development of Canadian physiotherapy. Physiotherapy Canada 1989; 41(2).

55. Heap R. Physiotherapys quest for professional status in Ontario, 1950-80. Canadian Bulletin of M edical History 1995; 12(1):69-99.

56. Chartered Society of Physiotherapy. Physiotherapy 100 Years. Journal of the Chartered Society of Physiotherapy 1994; 80(A).

57. Asociación Colombiana de Fisioterapia. Fisioterapia 53-83 - Los Pioneros de la Fisioterapia en Colombia. Edición especial. Bogotá: Asociación Colombiana de Fisioterapia; 1984.

58. Colegio de Kinesiólogos. Historia de la Kinesioterapia em Chile. [acessado 2007 Jan 20]. Disponível em: http://www.colegiodekinesiologos.cl

59. Organización Panamericana de la Salud. Scientific Institutions in Latin America: M unicipal Institute of radiology and physiotherapy. Boletín de la Oficina Sanitaria Panamericana 1941;20(2):153-56.

60. Peat $M$. The establishment of physical therapy in developing countries. Progress in Physical Therapy 1970; 1(3):236.
61. Arquivos da Escola de Educação Física e Desportos Rio de Janeiro: Escola de Educação Física e Desportos; 1945.

62. Relatório de 1958. Rio de Janeiro: Escola de Educação Física e Desportos; 1958.

63. Atas de reunião da Congregação da Escola de Educação Física e Desportos. Livro no 1. Rio de Janeiro: Congregação da Escola de Educação Física e Desportos; 1939.

64. Hindley-Smith R, Louza JR. O técnico em fisioterapia na medicina moderna. Revista Paulista de H ospitais 1959; 7(12).

65. ONU. Departamento de assuntos econômicos y sociales de las Naciones Unidas. Nueva York: ONU; 1965.

66. Brasil. Portaria de GR 347 de 7 de abril de 1967 Diário Oficial da União 1967; 13 abr.

67. Organización Mundial de la Salud. Comite de Expertos em Rehabilitation Medica - Primer Informe. Genebra: OM S; 1958. [Serie de informes técni$\left.\cos n^{\circ} 158\right]$

68. Baptista H. A história da medicina de reabilitação. M edicina de Reabilitação 1988; (19):17-18.

69. ABBR. Livro de presenças às solenidades da Associação Brasileira Beneficente de Reabilitação. Rio de Janeiro: ABBR; 1956.

70. Amaral AC, Oliveira NV. Cinesiologia e reabilitação. Volume 1. Rio de Janeiro: Editora Rio; 1960.

71. ABBR. Regimento Interno da Escola de Reabilitação da ABBR. Rio de Janeiro: ABBR; 1958.

72. Conselho Nacional de Educação. Processo no 97.990/ 61. Câmara de Ensino Superior, CES/CNE, 1961A.

73. Conselho Nacional de Educação. Parecer n $n^{\circ} 602 / 61$. Câmara de Ensino Superior, 1961B.

74. Brasil. Lei no 4.024 de 20 de dezembro de 1961. Fixa as diretrizes e bases da educação nacional. Diário Oficial da União 1961; 22 dez.

75. Conselho Federal de Educação. Parecer n 362/63. Câmara de Ensino Superior, 1963A.

76. Conselho Federal de Educação. Parecer n 388/63. Câmara de Ensino Superior, 1963B.

77. Brasil. Ministério de Estado da Educação e Cultura. Portaria M inisterial no 511/64, 1964.

78. Conselho Federal de Educação. Parecer no 715/65. Câmara de Ensino Superior, 1965.

79. Congresso Nacional. Projeto $n^{\circ} 2.090-B$. Modifica o Decreto-Lei no 938. Diário do Congresso N acional 1972. 9 mai. [seção I, páginas 771 e 772]

Artigo apresentado em 10/09/2007

Aprovado em 17/12/2007

Versão final apresentada em 04/04/2008 